\title{
ALGUNOS ASPECTOS HISTÓRICOS DEL HABLA PANAMEÑA
}

En la dialectología del español que se habla en América no se ha aclarado todavía la situación del istmo de Panamá. Esta región ha recibido diversas influencias lingüisticas debido a su posición geográfica, pues está situada como punto de división entre varias de las grandes zonas provisionales de la lengua en América sugeridas por Pedro Henríquez Ureña ${ }^{1}$. Al Oeste linda con la de México y la América Central; al Este sin duda ha habido contactos con la zona de las Antillas (por las costas septentrionales de Colombia) y con la del Norte y Oeste de la América del Sur (debido a la hegemonía política y cultural de Bogotá durante los siglos XviII y XIX).

Muchos de los problemas que encuentra el investigador nacen del hecho de que desde tiempos remotos Panamá ha sido un punto de tránsito. A los indígenas prehispánicos les servía de puente entre dos continentes, cosa que resulta evidente cuando se examina la variedad de culturas y lenguas que encontraron los europeos al llegar al Istmo ${ }^{2}$. Durante la época colonial fué lugar de tránsito entre los dos océanos y lo sigue siendo hoy para todas las naciones del mundo. Los españoles no tardaron en establecer el servicio de recuas de mulas entre Panamá la Vieja y Nombre de Dios (y después Portobelo) para el transporte de mercaderías y oro; y hasta 1739 fué la única ruta de comercio entre España y el Oeste de la América del Sur. En el siglo XIx, con la construcción del ferrocarril a través del Istmo, se inició otro período de actividad; a mediados del siglo comenzó el contacto entre el español y el inglés, que todavía se mantiene vivo, con la independencia política de Panamá y las obras del canal que se emprendieron poco después.

Sin embargo, la mayor parte del territorio panameño ha quedado fuera de las rutas de tránsito. Por falta de comunicaciones se mantuvo en aislamiento comercial y cultural gran parte del territorio durante la colonia. Comentando el atraso de Panamá, escribía el colombiano Felipe Pérez en 1862:

1 "Observaciones sobre el español en América", RFE, VIII, 1921, pág. 360.

"Véase Samuel K. Lothrop, "The archeology of Panama", en Handbook of South American Indians, vol. IV, Washington, 1948, págs. 143-167. 
Con todo, los galeones i el tránsito de las mercaderías i el oro del Perú dieron sólo un lustre i una prosperidad efímeras a una pequeña parte del territorio del Estado, pues sus benéficos efectos apenas se hacían sentir en el interior de las antiguas provincias de Veragua i Chiriquí ${ }^{3}$.

La independencia política y el período de dominio colombiano no causaron cambios notables, y el estado de aislamiento del Occidente del Istmo sólo ha llegado a su fin en el siglo àctual con la construcción de carreteras y la introducción de rutas aéreas. Al Este de la capital las selvas del Darién todavía resisten a la penetración del hombre, y la mayoría de sus pocos habitantes viven en tribu ${ }^{4}$.

Para el investigador del español de Panamá, la región que menos problemas ofrece es la que se extiende desde la Zona del Canal hacia el Oeste y abarca las llanuras de las provincias de Panamá, Coclé, Herrera, Los Santos, Veraguas y Chiriquí, hasta llegar a los confines de Costa Rica. Su población, escasa durante la colonia, ha aumentado lentamente después sin sufrir inmigraciones violentas ni marcadas influencias de otras culturas. Los relatos de la conquista y del período de la colonia dan una idea de ciertos aspectos de la sociedad y la cultura istmeñas que han intervenido en el desarrollo del español que hoy se habla en esta región. Los datos que tenemos son en gran parte negativos, pues, en vez de ayudar a explicar la presencia de ciertos fenómenos en la lengua, nos permiten comprender la ausencia de otros. A veces, sin embargo, hay datos preciosos que aclaran uno que otro punto de interés lingüístico. En su mayoría revelan el proceso de la rápida extensión del uso del español entre la población indígena. Por consiguiente, desarrollaré como tema principal esta extensión del español, indicando a la vez otros puntos que sirvan para comprender el estado lingüístico de la era colonial.

Los conquistadores españoles no encontraron en el Istmo un estado lingüístico del todo uniforme. En la mitad oriental hallaron varias tribus que hablaban el cueva, lengua de afiliación chibcha que tenía varios dialectos. Su límite occidental era el pueblo de Chame, situado a unos cincuenta y cinco $\mathrm{kms}$. al Sudoeste de la actual ciudad de Panamá ${ }^{5}$. Al Oeste de Chame existían varios cacicazgos que hablaban otras lenguas de afiliación desconocida. Pas-

${ }^{3}$ Jeografía fisica i politica de los Estados Unidos de Colombia, Bogotá, 1862, vol. I, pág. 124.

* Censo de población, 1970. Informe preliminar, Panamá, 1943, pág. 34.

"Relación de los sucesos de Pedrarias Dávila en las provincias de Tierrafirme, y de lo ocurrido en el descubrimiento de la Mar del Sur y costas del Perí y Nicaragua, escrita por el adelantado Pascual de Andagoya, en José Toribio Medina, El descubrimiento del Océano Pacifico, Santiago de Chile, 1913, vol II, pág. 201. 
cual de Andagoya, adelantado de Pedrarias, indica que los de Cherú tenían lengua distinta de la de Chame ${ }^{6}$; y según Gaspar de Espinosa, alcalde mayor de Pedrarias, los indios de Escoria, otra provincia cercana, hablaban lengua distinta de la de Cherú ${ }^{7}$; también la de Esqueva, otra provincia que estaba al Oeste, era diferente de todas las demás de la comarca ${ }^{8}$. Andagoya observa sobre el territorio situado al Oeste de Natá, cacicazgo principal del Golfo de Parita: “...y desde Burica hasta esta provincia que se dice Tobreitrota [= Tobré y Trota], casi que cada señor es diferente de lengua uno de otro" ". Los indios de dicha región, desde Punta Burica, en lo que hoy es frontera entre Costa Rica y Panamá, hasta el Norte de la actual provincia de Coclé, hablaban sin duda dialectos de filiación chibcha, pues sus descendientes que han quedado recluídos en las serranías de las provincias de Veraguas, Chiriquí y Bocas del Toro todavía hablan guaymi, dialecto del chibcha ${ }^{10}$. Los cronistas de la época apuntan y explican muchos vocablos del cueva y algunos del guaymi ${ }^{11}$.

Después de los primeros viajes de navegación y exploración, el contacto efectivo entre el español y las lenguas indígenas comienza en las primitivas colonias españolas del Istmo, Santa María la Antigua (fundada en 1510) y Acla (1517), ambas en tierras del cueva. Se extiende este contacto con las expediciones a otras partes del Istmo, como la de Balboa al Pacífico (1519), la de Gonzalo de Badajoz hasta la península de Azuero (1515) y las de Gaspar de Espinosa al Oeste del territorio (1516 y 1519 ). De pocos años después datan las primeras poblaciones de índole permanente, Panamá (1519) y Natá (1521 ó 1522). En 1519 , Pedrarias concede en repartimiento más de ocho mil quinientos indios del centro y el Este del Istmo ${ }^{\mathbf{1 2}}$. No tarda en sobrevenir una rápida disminución de la población indígena, y el retraimiento de los sobrevivientes a núcleos aislados en distintas regiones del territorio panameño: los chocóes, en las selvas del Darién; los cunas, en las islas y las selvas de la costa caribe

- En Mrdina, loc. cit.

"Relación e proceso quel licenciado Gaspar de Espinosa, alcalde mayor, hizo en el viaje que por mandado del muy magnifico señor Pedrarias de Ávila, teniente general en estos reinos de Castilla del Oro por Sus Altezas, fué desde esta cibdad de Panamá a las provincias de Paris e Natá e a las otras provincias comarcanas [1519], en MEdina, vol II, pág. 283.

8 En Medina, vol. II, pág. $\mathbf{2 8} 5$.

- Relación de los sucesos ..., en Medina, vol. II, pág. 199.

${ }^{10}$ Véase Lothrop, art. cit., pág. 143.

11 Estos vocablos se encuentran reunidos en la obra de Walter LehmanN, Zentral-Amerika, Berlin, 1920, vol. I, págs. 112-122.

${ }^{12}$ Véase El proceso que vino por apelación del Licenciado Gaspar de Espinosa, vecino de Tierra Firme, ques con el Licenciado Salmerón, oidor de la Nueva España, sobre el interés de los indios, en Medina, vol. II, págs. 445-462. 
del Oriente del Istmo; y los guaymies que ya he mencionado ${ }^{13}$. Según los cálculos más fidedignos, existían en esta época alrededor de 800,000 indígenas en lo que es el actual territorio de Panamá ${ }^{14}$.

Para comunicarse con los indígenas, los españoles se valieron al principio de intérpretes. Gaspar de Espinosa indica que así comenzó la evangelización de los indios de Natá, donde pasó unos cuatro meses en 1516 . Espinosa relata que "el padre vicario les predicaba, por una lengua intérprete, nuestra santa fee católica; aprovechaba mucho, porque los mochachos e mujeres muchos dellos pidían que los tornasen cristianos, que lo querían ser, que los gandules e indios mayores es cosa excusada, si Dios no inspira en ellos" 15 . El cronista no identifica aquí al intérprete; tal vez haya sido un indio "Martinico, que era ladino", mencionado por Espinosa en otra ocasión ${ }^{16}$. Cuando Espinosa vuelve a Natá en agosto y septiembre de 1519, menciona a otros intérpretes que le sirven en los procesos contra los caciques e indios principales de la región. Por lo menos tres de sus intérpretes son mujeres, como se ve en el proceso contra el cabra o indio principal, llamado Ibrery:

... fasta quel dicho cabra Ibrery e los dichos indios dixeron que lo entendían muy bien, por la dicha Violante, lengua, e Francisca e Catalina, indias ladinas desta dicha provincia de Natá, e les dixo e platicó e dió a entender por las dichas lenguas cómo habrían de ser vasallos de Sus Altezas e cómo habían de servir a los cristianos ... ${ }^{17}$

Además, menciona ${ }^{18}$ a Juanico, otro indio de Natá que le sirve de lengua. Aunque los cronistas del período muestran cierta familiaridad con el vocabulario de los idiomas indígenas, no parecen haber adquirido un dominio suficiente para usarlos en el trato oficial con los indios.

No hay pruebas de que los religiosos encargados de enseñar la doctrina cristiana a los indios hayan aprendido las lenguas de éstos, por lo menos durante el siglo xvi. Tampoco existen "artes" de las lenguas nativas para uso de los frailes, como las compuestas en México, por ejemplo ${ }^{19}$. Las relaciones de las tareas evangelizadoras

${ }^{13}$ El censo de 1940 indica un total de 64,960 indigenas, en una población de 631,549 habitantes (Censo de población, 197o. Informe preliminar, pág. 34).

14 Manuel María Alba, "Etnología y población histórica de Panamá", en el Boletín de la Academia Panameña de la Historia, I, 1933, pág. 235.

${ }^{15}$ En Medina, vol. II, pág. 168.

16 Ibid., loc. cit.

17 Ibid., vol. II, pág. 311 .

18 Ibid., vol. II, pág. $3^{14}$.

19 Para el territorio del Istmo, Lehmann apunta (vol. I, pág. 102) solamente un caso durante el período de la colonia: el del P. Ignacio Franciscio, quien por 1740 escribe gramática, vocabulario y catecismo "en lengua dariela" (men- 
de los religiosos no dan sino escasos datos sobre la situación lingüística de los indios, aunque sí muestran el estado de desmoraliżación de éstos como resultado de la conquista. Es lo que se refleja en la carta escrita al Rey en $15^{61}$ por fray Pedro de Santa María ${ }^{20}$, dominico que tenía ya unos diez años de labor entre los indios de Natá. Por desgracia no comenta sus métodos, aunque dice que "ya por la bondad de Dios Nuestro Señor son todos christianos, y los é casado y administrado los demás sacramentos" ${ }^{21}$.

A mediados del siglo xvi, el gobernador Juan Ruiz de Monjaraz mandó fundar los pueblos de Los Santos, Parita y Olá, donde se reunió a los indios dispersos del interior que no habían huído a la cordillera central del Istmo, para mejor doctrinarlos. Con el mismo motivo se fundaron otros pueblos; y este programa de colonización y enseñanza no tardó en extender el uso del español entre los naturales. Debe de haber sido eficaz, porque en una carta al monarca, escrita en $160_{5}$ ó 1606 , el obispo de Panamá habla de los indios de varios pueblos de Veragua y los compara con los de Chiriquí. Observa el obispo "que los que ay en San Pedro del Montijo y en Santa Fee [pueblos de Veragua] son más ladinos, que casi hablan con nuestro propio lenguaje, y andan vestidos los que yo vi, que como cosa nueva me venían a ver ..." ${ }^{22}$ En esta época ocurría otro tanto entre los indios de Chepo, pueblo situado al Este de la ciudad de Panamá. En la Descripción de Panamá y su provincia, hecha por la audiencia en 1607 , se dice de estos indios: "Hablan la lengua castellana y an oluidado del todo la suya. También se visten a la española jubones y çaragüelles; no ay ninguno que sepa leer" ${ }^{23}$. En el mismo año, el obispo de Panamá resume el estado lingüístico de los indios del Istmo: “... . es que en este Reyno de Tierra Firme ay cinco pueblos de yndios fundados muchos años a, que los naturales dellos son yndios de mucha rraçón para yndios, y que no saven hablar otra lengua sino la nuestra ..."24 Estos pueblos eran Penonomé y Olá (de la actual provincia de Coclé), Atalaya (provincia de Veraguas), Parita (provincia de Herrera) y Chepo, situados todos en tierras bajas, en las llanuras cercanas al Pacífico, y por consiguiente en contacto con los españoles que habían establecido ya sus estancias de ganado en aquellas regiones. Dentro de los noventa años

cionado por Lorenzo Hervás, Catálogo de lenguas de las naciones conocidas, vol. I, Madrid, 1800 , pág. 280).

20 En León Fernández, Colección de documentos para la historia de Costa Rica, París, 1886 , vol. IV, págs. 188-193.

${ }^{21}$ Ibid., pág. 188.

${ }^{22}$ Ibid., vol. V, pág. $13^{2}$.

${ }^{23}$ Colección de libros y documentos referentes a la historia de América, vol. VIII, Madrid, 1908, pág. 144.

24 En Fernández, vol. V, pág. 143. 
después de la conquista, los indios de las tierras bajas habían perdido su lengua propia y ya hablaban español.

No sucedió así en las tierras altas del centro del Istmo. Los españoles no emprendieron la conquista de los indios de las montañas del Norte de Coclé hasta principios del siglo xvir. En 1603 Juan López de Siqueyra, gobernador de Veragua, en carta al monarca, dijo que pensaba conquistar en aquel año los dichos indios ${ }^{25}$. Estos indios, llamados hoy cholos, término que en Panamá se refiere a los 'indios que ya no viven en tribu y han adoptado las costumbres del europeo', todavía dan indicios de una reciente asimilación a la cultura hispánica.

Durante la época colonial tuvieron las autoridades españolas constante preocupación por la evangelización de los indios guaymies que todavía habitan la cordillera central del Oeste del Istmo. Los resultados de este empeño no fueron del todo satisfactorios: los indios que vivían más cerca de los centros de población española, como los de Cañazas y Las Palmas en Veraguas y Remedios, y Alanje, Dolega y Gualaca en Chiriquí, aceptaron la cultura y la lengua de los españoles, pero otros núcleos de indígenas quedaron recluídos en los valles apartados de la sierra. Aquí también los misioneros se valieron de intérpretes para predicar, como sucedió en las entradas que por 1625 hizo el dominico limeño fray Adrián de Santo Tomás a la región oriental de Chiriquí ${ }^{26}$.

A principios de 1787 , el sargento retirado Manuel de Jesús Atencio hizo un viaje de reconocimiento a la costa septentrional de la provincia de Veragua. En su relación indica Atencio que gran parte de los indios de la región ignoraban el español y sólo hablaban el guaymi, pues él se comunicaba con ellos por medio de intérpretes. Hay en esta relación un pasaje curioso en que Atencio remeda el modo de hablar español de un indio ladino:

... fué preciso regalarles eslabones, anzuelos, espejos y chaquiras, y los indios quedaron contentos y preguntaron quiénes eran los capitanes de esta gente, y les dije que yo y este hombre que es el práctico, y nos dijeron "pobre sulia, traer mucha hambre, coman, indio cuando va a tu tierra no regalando nada, come él todo queriendo por plata, indio pasando mucha necesidad", y nos regalaron algunas yucas, y aquí en esta dormida hemos hecho noche ${ }^{27}$.

Estos indios todavía conservan su propio idioma, un dialecto del

${ }^{25}$ Ibid., vol. V, págs. 109-115.

${ }^{28}$ Juan Requejo Salcedo, Relación histórica y geográfica de la Provincia de Panamá [1640], en Colección de libros y documentos referentes a la historia de América, vol. VIII, pág. 100.

${ }^{27}$ En Antonio B. Cuervo, Colección de documentos inéditos sobre la geografia y la historia de Colombia, Bogotá, 1891, vol. I, pág. 326 . 
chibcha, y su estado lingüístico parece haber cambiado poco desde las postrimerías de la época colonial. Su influencia sobre el idioma predominante es poca o nula, debido a su poco contacto con el español y a su atraso cultural.

Falta todavía comentar otro elemento extrahispánico en la sociedad colonial: los negros. Les atrae el trabajo de las minas del Norte de Veragua, desde 1556 , y también el servicio de recuas de mulas entre Panamá y la costa del Atlántico. De su medio de expresión durante la colonia tenemos un solo dato, referente a la capital del Istmo, y del año 1607. El autor de la Descripción de Panamá y su provincia reseña con las siguientes palabras el estado lingüístico de la capital: "En la ciudad no hay indios; los españoles hablan la lengua castellana; los negros entre sí, los de cada tierra la suya; también hablan castellano, pero muy mal, si no son los que dellos son criollos". Los negros, al parecer, pronto aprendieron el español, pues en la ciudad vivían en estrecho contacto con este idioma porque muchos de ellos servían de criados en las casas. En ese período habitaban en la capital 3,771 esclavos y 148 negros horros, además de $14^{6}$ mulatas ${ }^{28}$.

En la consideración de la extensión del español por los territorios del Istmo no debe omitirse el problema de su escasa población durante la época de la colonia. La despoblación se inició cuando llegaron a Panamá las noticias de las fabulosas riquezas que habían encontrado los conquistadores en el Perú. El Istmo no poseía tales atractivos para el inmigrante. A pesar del comercio que tuvo que pasar por Panamá durante este período, no llegó a establecerse un centro urbano notable. Hacia fines del siglo xviII la capital sólo tenía 7,857 habitantes ${ }^{29}$.

La población rural, sin embargo, tuvo un crecimiento regular desde mediados del siglo xvi. Las tierras llanas situadas al Oeste de la capital pronto llegaron a ser una región abastecedora de comestibles para Panamá, Nombre de Dios y después Portobelo. Poco a poco estas estancias de ganado se fueron extendiendo hacia el Oeste por Chorrera, Chame, Antón, Natá, Parita y Santiago hasta llegar a Chiriquí ${ }^{30}$. Las estancias o hatos, como se denominan en Panamá, han tenido un papel importante en la formación de la estructura social del interior del país. Al principio eran casas aisladas para el abrigo de los vaqueros, pero alrededor de ellas se fueron constru-

${ }^{28}$ Col. de libros y doc. referentes a la hist. de América, vol. VIII, págs. 162 y $166-169$.

${ }^{29}$ Según Enrique J. Arce y Ernesto J. Castillero, Guía histórica de Panamá, Panamá, 1942, pág: 6o.

${ }^{30}$ Explica este proceso el Dr. Eusebio A. Morales en su estudio "La pobla. ción del Istmo" (en Ensayos, documentos y discursos, Panamá, s. f., vol. II, pág. 6) . 
yendo caseríos, hasta llegar a formar pequeños centros de población. Tal vez sea el pueblo de Antón (provincia de Coclé) el ejemplo más típico de este proceso. En la toponimia local pueden verse todavía reflejos del sistema, pues casi no hay distrito del interior que no tenga su "hato"; por ejemplo, Rio Hato, del distrito de Antón, Hato de San Juan de Dios, cerca de Aguadulce, y Los Hatillos, al Sur de Santiago de Veraguas. EI marcado sabor rural del español del interior puede atribuirse en gran parte a este fenómeno económico y social de la era colonial.

La falta de un sentimiento bien dispuesto hacia la instṛucción también ha dejado sus huellas. Fn la capital ha predominado la inclinación al comercio; por eflo ha sido escasa su influencia cultural sobre los pueblos del interior. Se nos dice ${ }^{31}$ que en el período colonial el cura de la parroquia enseñaba los rudimentos de la instrucción. A veces los maestros españoles enseñaban lectura, escritura y doctrina cristiana. Tampoco en la capital parece haber sido muy adelantada la instrucción. La Descripción de Panamá y su provincia, escrita en 1607, nos dice: "No ay seminario en Panamá. Un maestro enseña a leer y escrivir pagándole los muchachos, sin otro salario más de que la ciudad le da casa de valde. En el colegio de la Compañía se enseña latinidad, y la ciudad les paga por ello a los padres trescientos pesos corrientes al año" 32 .

La falta de educación superior en la colonia contrasta mucho con el adelanto de Lima, México y Santo Domingo. No hubo universidad en Panamá hasta 1749; en esta fecha, por iniciativa del obispo panameño don Francisco Javier de Luna Victoria y Castro, establecieron los jesuítas la Universidad de San Javier. Se enseñó allí latinidad, retórica y teología moral; pero en 1767 , con la expulsión de los jesuítas, tuvo que suspender sus actividades y no volvió a abrir sus puertas.

Ahora examinaré los aspectos del habla contemporánea en que el investigador debe buscar las huellas más importantes de los hechos históricos ya tratados.

Los cronistas españoles de la época de la exploración y la conquista del Istmo emplean con bastante frecuencia vocablos tomados de las lenguas indígenas de la región. Estos términos provienen en su mayoría del cueva, el idioma predominante del centro y el Oriente de Panamá. Walter Lehmann ${ }^{33}$ apunta y comenta cuarenta y ocho de estos vocablos, que se refieren en gran parte a la organización social de los indios y a la fauna y flora de la región. De éstos todavía se

${ }^{31}$ Juan B. Sosa y Enrique J. Arce, Compendio de historia de Panamá, Panamá, 1911, pág. 179 .

${ }^{32}$ Col. de libros y doc. referentes a la hist. de América, vol. VIII, pág. 215.

${ }^{33}$ Zentral-Amerika, op. cit., vol. I, págs. 112-122. 
usa espavé, que designa 'el árbol Anacardium rhinocarpus' (a principios del siglo Xvı espavé significaba 'mujer del cacique'). Hay también el caso dudoso de chicha, que según las palabras de Oviedo ${ }^{34}$ parece ser de origen panameño, aunque Henríquez Ureña opina ${ }^{35}$ que proviene del taíno. En la actualidad han desaparecido hasta las palabras regionales más usadas por los escritores de la conquista, como cabra 'capitán' ${ }^{36}$, ira 'mujer', ochi 'tigre, pantera', saco 'cacique, tequina 'médico, maestro' y tiba 'señor'. Sobreviven en la toponimia unos cinco términos: Beragua o Veragua 'río aurífero', Capera o Capira 'árbol Panamá, Sterculia apetala Jacq.', Coiba 'lejos', Panamá 'lugar donde se toma mucho pescado' y Tuyra 'diablo'. Se ha perdido en gran parte el sentido original de estos vocablos regionales, sobre todo en la toponimia. Por ejemplo, Veraguas, nombre de una provincia, se explica popularmente a base de "ver aguas", debido a su clima lluvioso. También Penonomé, nombre de la capital de la provincia de Coclé, se suele explicar a base de una etimología popular que ha adquirido uso corriente, aunque carece de fundamento: se cree que en este lugar pereció un cacique indio llamado Nomé, y que el nombre del pueblo resultó de la frase "aquí penó Nomé" 37 . En las crónicas se escribe en la época más temprana Pananomé, y así se llamaba el cacique, según Pedro Mártir y Las Casas ${ }^{38}$.

Con el corto número de regionalismos de origen panameño contrasta claramente la vitalidad de los americanismos de procedencia antillana, principalmente del taíno, la lengua de los arahuacos de las Bahamas y las Grandes Antillas. Este hecho se debe en gran parte al papel de las Antillas, sobre todo Santo Domingo, en la historia lingüística de América. La Isla Española, como observa Cuervo, "fué

${ }^{4}$ Gonzalo Fernández de Oviedo, Historia general y natural de las Indias, ed. de Madrid, $185^{1-1855}$, vol. III, pág. 136 .

${ }^{35}$ Para la historia de los indigenismos, Buenos Aires, 1938, pág. 113.

${ }^{36}$ Todavía en 1640, Requejo Salcedo emplea el término cabra en su relato de las labores apostólicas de fray Adrián de Santo Tomás entre los guaymies (cf. Colección de libros y doc. referentes a la hist. de América, vol. VIII, pág. 99).

${ }^{37}$ Luisita Aguilera Patiño, el panameño visto a través de su lenguaje, Panamá, s. f., pág. 372. La autora ofrece (págs. 113114) una explicación parecida en el caso del aztequismo guachapali, nombre del árbol Acacia guachapale y también de un barrio de la ciudad de Panamá: cree que el nombre tiene su origen en el inglés de los negros antillanos residentes en el barrio, que habían construído allí una white chapel 'capilla blanca', de donde guachapali. Sin embargo, se encuentra documentada la variante guachapeli en la Descrip. ción de Panamá y su provincia, escrita en 1607 (Col. de libros y documentos referentes a la hist. de América, vol. VIII, pág. 146).

38 Pedro Mártir de Anglería, Décadas del Nuevo Mundo, Buenos Aires, 1944, pág. 295; Bartolomé de las Casas, Historia de las Indias, México y Bueṇos Aires, 1951, vol. III, pág. 64. 
en América el campo de aclimatación donde empezó la lengua castellana a acomodarse a las nuevas necesidades" ${ }^{39}$.

Estos vocablos entraron en el español de Panamá desde los primeros años de la colonia, porque se encuentran ya en las cartas y relaciones de Balboa, Pedrarias, Gaspar de Espinosa y Pascual de Andagoya, y en las informaciones de méritos de varios de los soldados y oficiales de la conquista. Algunos de los pobladores de esta época ya eran vecinos de la Isla Española, y los españoles recién salidos de la Península podían quedarse en la isla durante el tiempo necesario para abastecer los navíos y formar las expediciones que habían de seguir hacia el continente ${ }^{40}$.

El cronista Gonzalo Fernández de Oviedo describe el proceso de la extensión de los antillanismos cuando explica el uso de la palabra cacique en Panamá: "aqueste nombre caçique no es de la Tierra Firme sino propriamente desta Isla Española, e como fué esto lo primero que poblaron e ganaron los christianos, ellos han dado este nombre cacique a los señores de otras partes por donde en estas Indias han discurrido" ${ }^{41}$.

Gran parte de los antillanismos introducidos durante el período más temprano de la colonización del Istmo son ahora patrimonio del español general, o se usan en grandes regiones de América: barbacoa, bohio o buhio, cabuya, cacique, canoa, caribe, haba (con $h$ aspirada), hamaca (a veces con $h$ aspirada), iguana, macana, maiz, mamey, nequén (henequén, que puede ser préstamo del maya ${ }^{42}$ ), sabana, tiburón, yuca. Algunos otros ya han desaparecido del español de Panamá, y se hallan sólo en los documentos de la primera mitad del siglo xvi: aje ${ }^{43}$, arcabuco, areito, bateyn (juego de pelota

39 Rufino J. Cuervo, El castellano en América, Bogotá, 1935, pág. 73 .

${ }^{\circ}$ Vasco Núñez de Balboa explica la necesidad de la adaptación del colono al nuevo ambiente cuando dirige una carta al rey pidiendo el auxilio necesario para asegurar la población de Tierra Firme. Escribe desde Santa Maria la Antigua en 20 de enero de 1513: “... lo principal, es menester que vengan mil hombres de los de la Isla Española, porque los que agora viniesen de Castilla no valdrían mucho fasta que se ficiesen a la tierra, porque al presente ellos se perderían y los que acá estamos con ellos". En Medina, El descubrimiento del Océano Pa. cifico, op. cit., vol. II, pág. 135 .

${ }^{41}$ Historia general y natural de las Indias, ed. cit., vol. III, pág. 129.

42 Cf. Henríquez Ureña, Para la historia de los indigenismos, pág. 113.

43 Ibid., págs. 59-86, donde Henríquez Ureña discute "El enigma del aje". Se cita esta planta en dos ocasiones, pero los cronistas de la época no la identifican. El alcalde mayor Gaspar de Espinosa la menciona en ${ }_{15}^{19}$ como uno de los productos de las tierras de Antatara, cacique de París: “... sin consentir que nadie se parase a comer ni a facer otra cosa, puesto caso que había muchas pavas e iguanas e tórtolas e bollos e iguana e ajes e chicha, nos volvimos al dicho Asiento Viejo..." (en Mrdina, vol. II, págs. 201-202). El adelantado Pascual de Andagoya escribe sobre el territorio del cacique de Natá: "Todas estas tierras son finas y llanas y muy hermosa tierra, de muchos mantenimientos, 
de los indios de Haití), guaçábara, guanin, naboria. Las descripciones y relaciones compuestas en el siglo Xvir revelan de manera más amplia el uso de los antillanismos en el léxico panameño ${ }^{44}$. Hacia esta época ha habido ya un siglo de contacto continuo y activo entre el Istmo y Santo Domingo. Al parecer, las palabras de origen antillano han pasado su período de más rápida extensión, y su número se aproxima al que tienen en el vocabulario panameño de la actualidad.

Fn la consideración del desarrollo de la pronunciación del español de Panamá, sería difícil comprobar la existencia de huellas fonéticas que se puedan atribuir a las lenguas indígenas. La rápida y temprana extensión del español entre los indios, cuyo número disminuyó grandemente en la primera mitad del siglo xvI, parece haber borrado cualquier rasgo fonético de tales idiomas. Pocos son los datos precisos que tiene el investigador acerca de la pronunciación en la época colonial. Existe, sin embargo, una nota curiosa de las postrimerías de la colonia. Un escritor anónimo nos revela su impresión del español de Panamá: “. . y y los del país hablan con flojedad o desmayo en las voces, por un efecto tal vez del temperamento ardiente" ${ }^{45}$. Aquí entra ya la teoría climatológica como explicación de los fenómenos fonéticos. No se puede precisar si la observación se refiere a la entonación o a la manera relajada de formar algunas de las articulaciones, por ejemplo la $j$ y la $s$, todavía evidente, sobre todo en el habla rural. Pero aquí no encontramos necesariamente una influencia extrahispánica.

En Panamá es probable que dé más fruto una investigación de las corrientes que pueden provenir de la dialectología peninsular

de maíz y ajes y melones, diferentes de los de acá..." (Medina, vol. II, pág. 280). En el habla rural de Panamá, aje tiene hoy el valor de 'desaire, ultraje' (cf. Sebastián Sucre, "Provincialismos panameños," en BAPaL, VII, 1933, núm. 7 , pág. 33 .

*4 Fuera de Juan Requejo SAlcedo, Relación histórica y geográfica de la Provincia de Panamá y la anónima Descripción de Panamá y su provincia, obras ya mencionadas, hay otras dos en la Colección de documentos inéditos del Archivo de Indias, vol. IX, Madrid, 1868, que son una descripción de la ciudad de Panamá (págs. 79-108), escrita en 1610, y otra en Portobelo (págs. 108-120), compuesta en 1607. En estas reláciones son escasos los ejemplos de americanismos derivados del náhuatl y el quechua. Requejo Salcedo trae los nahuatlismos súchil y aguacate (pág. 74), y chicosapote (pág. 75); en la Descripción de Panamá y su provincia hallamos guachapeli (pág. 146) y la "yerua llamada Mechocán" (pág. 15o). Del quechua sólo hay dos: papa (Requejo SAlcedo, pág. 76) y çapallo (Colección de documentos inéditos de Indias, vol. IX, pág. 96).

${ }_{45}$ Ciudad de Panamá, capital de su distrito y estaciones del año, obra compuesta a principios del siglo xix, impresa en Antonio B. Cuervo, Colección de documentos inéditos sobre la geografía y la historia de Colombia, op. cit., vol. II, pág. 342 . 
y de las zonas circunvecinas del español de América. Éstas deben estudiarse tomando en cuenta las circunstancias aquí discutidas, sin pasar por alto la vida cultural de la colonia panameña, con su población a veces transitoria, su interés por el comercio y la relativa falta de actividad educativa y literaria.

Stanley L. Robe

University of California,

Los Angeles. 